\title{
A Brief Analysis of Methods and Approaches of Using Conformist Mentality of Students to Carry out Ideological cal and Political Education
}

\author{
BAI Bing \\ Wuhan University of Science and Technology Wuhan, China \\ baibing@wust.edu.cn
}

\begin{abstract}
Conformist mentality is a common social psychological phenomenon in daily life and at work. The way of guiding university students to have a right attitude toward conformist mentality has a great significance for cultivation of ideological morality and good individual characters. This paper conducts a sample survey with A university and Technology as a target to analyze reasons of conformist mentality, probe into new methods and approaches of using conformist mentality of university students to carry out ideological and political education and regard effectively usage of university students' conformist mentality as the breakthrough point to carrying out political and ideological education work
\end{abstract}

Keywords: conformist mentality, ideological and political education education, methods, approaches.

\section{Introduction}

Conformity represents an important aspect of human psychology and has been extensively studied in social psychology since the pioneering work of Asch .[1]Rogers once pointed out: "Conformity of the young is possibly a compromise between going down with his need and keeping his personality. Even though they are convinced that keeping his personality is very important, they think it is necessary to be consistent with companions for being popular." Conformity is a phenomenon that individual voluntarily keep accordance with the majority of the group in following aspects such as recognition, judgment, faith, behavior and so on under group pressure[2]. Conformity determined by man's sociability and formed in long-term social practice run through the whole process of human being' social practice.

The costs of non- conformity to an individual include the costs of exclusion,behavioral costs and economic costs[3]. Conformist mentality, relatively prominent in university students' life, study and growth, is attributable to special stages of psychological development, group life sharing much common, influences of traditional culture, information society strengthening the dependence on groups and so on.

\section{The result of the survey of difference in college students' conformist mentality}

Taking 1147 university students from 44 majors in A university as samples, the research group designs, compiles and makes a questionnaire about conformist mentality of university students. According to research orientation of the research, the questionnaire has 69 questions and mainly includes two parts: The first one is basic information including sex gender, grade, family background and so on, the second part is conformist mentality's influence on cognitive behaviors of university students, which can be mainly divided into six following dimensions: study conformity, employment conformity, work conformity, life behavior, consumption conformity and habit conformity.

In order to have a better grasp of relations of dimensions, we make the statistical analysis showing that sex gender does not have a great influence on creation of university students' conformity behaviors. That means university boys and girls have conformist mentality and conformity behaviors with different degree. What's more, according to difference analysis, the degree of boys is higher than that of girls; Grade has influence on conformity behaviors of university students, according to correlation analysis, grade exerts a marked influence on conformity in following aspects such as study, employment, work, consumption and behavioral habit and exerts an influence on living 
behavior of conformity; majors have an influence on conformity behaviors of university students, which means there exists different degree of conformist mentality and conformity behaviors, slightly higher in science or engineering major on the whole; family background of university students has an influence on conformity behaviors of university students, which means there exists conformist mentality and conformity behaviors among university students either from cities or countryside, what' s more, conformist mentality and behavioral habit vary from each other because of different backgrounds. According to correlation analysis, the amount and degree of effect are different among individuals who are apt to be affected by conformist mentality. However, all of them will be influenced by factors.

\section{The reasons of university students' conformist mentality}

\section{Subjective Reasons}

\section{Poor independence and strong dependence.}

Nowadays, Many things are handled by parents and teachers instead of students themselves, as a result, students develop a habit of depending on others, so they rely on theirs to do many things as well as do as what parents and teachers require and do as others do.

\section{Insufficient understanding and judgment.}

Some university students have an insufficient understanding of themselves, some students lack required recognition of problems confronted. Human share the thought of drawing on advantages and avoiding disadvantages, thus they follow others judgments, believing group's wisdom and strength.

\section{Need of sense of belonging to group.}

The impact of other people's presence on our behavior is well-documented, and derives from two motivations: forming an accurate interpretation of reality and behaving correctly, and obtaining social approval from others[4].Human society consists of various relations formed by interaction between people. An individual will be frightened when his or her thoughts or actions deviate from a group for any group has certain mechanism, it is likely to be punished or abandoned if an individual deviates from a group. In order to gain a sense of safety and belonging of a group, an individual is apt to take the will of a group as the individual will.

\section{Objective Reasons}

\section{Influence of traditional culture.}

Psychologists think the reason why there is conformist mentality is group pressure. According to opinion of M.Deutsch and H.B.Gerard, group pressure can be divided into two kinds, which are information pressure and norm pressure. Information pressure means advice and information provided by others has significant effect on behavior of the individual. Information of others is an important part in life of the individual and people's experience of life shows that there is a stronger possibility of opinions of the majority of people[5].

Chinese excellent traditional culture bears a long history, which emphasizes "harmony". Harmony is regarded as a so precious and beautiful thing that gives people a false impression that a prevailing mood of harmony is normal.

\section{The influence of group environment.}

Each university student belongs to a group whose environment exerts a subtle influence on behavior and quality of university students. The impact of peer pressure on cognitive functions has been extensively studied[6].If the group has a high level of trust and strong cohesion, then members of the group tend to taking the group will as the individual will. As Owen says: the past, the present and the future of human will always be products of surroundings before and after the birth of human[7]. 
Since ancient times, there were such allusions. That Mencius' mother moves her home three times to better her son's education is a typical example that shows environment shapes human being. "He that lives with cripples learns to limp" also stresses influence of environment.

Methods and approaches of using conformist mentality of students to carry out ideological and political education

\section{Encourage innovative thinking and cast off thinking set.}

Zhang Ruimin had said: "Intelligence is more important than knowledge, quality is more important than intelligence while consciousness is much more important than quality."[8] This clearly demonstrates the importance of innovating, casting off thinking set and constantly breaking self.

We should encourage students to put forward doubts and various ideas as well as get more students involved in discussion, thus understanding true essence from own dialectic analysis. This will not only leave deep impression but also change situation of passive acceptance. Encouraging innovation and critical thinking can gradually change the way that most students accept ideological and political education and brim more vitality in ideological and political education.

\section{Develop campus culture and emphasize cultural diffusion.}

The theory put forward by Marx that the conformity between environmental change and human activity can only be reasonably regarded as revolutionary practice fully demonstrates the importance of cultural environment's effect on people[9]. Campus culture activity is an important carrier of intensifying ideological and political education. University campus is a vital place for students to live, study and work. For most of activities is held in campus, the level of construction of campus culture activities, the participation rate of classmates and the number of experience all directly or indirectly influence students' ideological and political quality.

\section{Attach great importance to mass organizations construction and education guidance.}

Confucius said: "The way of the great learning involves manifesting virtue, loving the people, and abiding by the highest good." Actually, this is an accurate and vivid explanation to the educational aim[10]. Construction and management should be reinforced in mass organizations in campus, We should lead members of mass organizations to struggle in line with positive and healthy education guidance and facilitate ideological and political level under the practice of mass organizations.

\section{Cultivate positive psychology and shape physical and mental health.}

Marx said: "Any reform is that gives the relationship between people and the world back to us." We should spare no efforts to accelerate educational reform.[10] The High-level psychological quality will facilitate the cognitive level to questions and educational effect of ideological and political education. However, if it is in adjustable range, no damage to physical and mental health will be caused, whereas, the premise is that we should bear healthy psychological quality. Besides own characteristics, healthy psychology can also be assisted and adjusted by mental health educates class.

\section{Set a good example and emphasize ideology and morality.}

A large behavioral literature has demonstrated that formal controls can "crowd out" psychological motivations that would lead to desired behavior even in the absence of controls[11].A fine example is not only a power, but also a kind of momentum and a banner. The power of role models is to teach, encourage and motivate people. Social consciousness promotes the development of social existence.

\section{Build clear network and enhance one's political consciousness}

With constant promotion and development of our education digitized, networked and informationalized, With the aim of implementing significant requirements of General Secretary Sip 
Kin-ping and the Party Central Committee and mobilizing all youth to actively participating the establishment of clear website, Mission Central and Chinese Adolescent News Media Association proposed youth volunteer action for network civilization. They called upon youth to pass on positive energy instead of believing and spreading rumors and build clear network to refine network environment and facilitate network civilization, take the opportunity of this initiative to launch and organize undergraduates in youth volunteer action for network civilization.

As college ideological and political educators, we should know study and analyze psychological characteristics. All need us to constantly and deeply understand undergraduate psychological characteristics and be adept in control and make use of advantages and rules of educational psychology, thus reinforcing effectiveness of ideological and political education work.

\section{References:}

[1]Nicolas Claidie 're, Mark Bowler, Andrew Whiten.Evidence for Weak or Linear Conformity but Not for Hyper-Conformity in an Everyday Social Learning Context. PLoS ONE. 2012, Vol. 7,Issue 2, p1-8

[2] Fang Hongzhi, Zhu Ling. Observe the Development of Ideological and Political Education from the Conformist Mentality of Undergraduates [J]. Gansu Union College Journal (JCR-SSCI), 2013, 29(2)

[3]Chris Doucouliagos. Conformity, replication of design and business niches. Journal of Economic Behavior \& Organisation.Vol. 30 (1996) 45-62

[4] Drew A. Curtis ,Donna M. Desforges .Less is More: The Level of Choice Affects Conformity.North American Journal of Psychology, 2013, Vol. 15, No.1, 89-102

[5] Lu Haidong. Educational Psychology [M]. Changchun, Northeast Normal University Press, 2002

[6] Nikolai Axmacher, Anna Gossen, Christian E. Elger, Juergen Fell.Graded Effects of Social Conformity on Recognition Memory. Plos One. 2010,Feb 17, Vol. 5 (2), pp. e9270.

[7] Li Dingren. Utopian Socialist Irving's Educational Thoughts [J].Northwest Normal University Journal (JCR-SSCI), 1973(3)

[8] Zhang Ruimin. Zhang Ruimin: consciousness is more important than quality [J]. The Original Composition: Gold Read and Write (for junior student), 2012(7)

[9] Zhou Jinhua. The New Exploration to Socialistic Biology, Jianghan Forum, 2003(10)

[10] Ye Wenling. Education must stick to guiding influence. Basic Eduaction lessons, 2007(6)

[11] W. B. TAYLER AND R. J. BLOOMFIELD .Norms, Conformity, and Controls.Journal of Accounting Research Vol. 49 No. 3 June 2011 Printed in U.S.A. 